0

\title{
Management of organic matter in watersheds with insufficient observation data: the Nakdong River basin
}

\author{
Jeonghoon Lee ${ }^{a}$, Ungtae Kimª, Lee-Hyung Kim ${ }^{\mathrm{b}}$, Eung Seok Kimc, Sangdan Kim ${ }^{\mathrm{d}, *}$ \\ ${ }^{a}$ Department of Civil and Environmental Engineering, Cleveland State University, Cleveland, OH 44115, USA \\ ${ }^{b}$ Department of Civil and Environmental Engineering, Kongju National University, 1223-24, Cheonan-daero, \\ Seobuk-gu, Cheonan, Chungcheongnam-do, 31080, Korea \\ 'Division of Architecture Engineering and Civil Engineering, Sunmoon University, 70, Sunmoon-ro 221 beon-gil, \\ Tangjeong-myeon, Asan, Chungcheongnam-do, 31460, Korea \\ ${ }^{`}$ Department of Environmental Engineering, Pukyong National University, 45, Yongso-ro, Nam-gu, Busan, 48513, \\ Korea, email: skim@pknu.ac.kr
}

Received 31 July 2018; Accepted 25 February 2019

\begin{abstract}
A B S T R A C T
Total organic carbon (TOC), which is represented as the total amount of organic matter in water, has emerged as a new water quality indicator. As TOC provides integrated information for managing water quality and sequential ecosystem of a watershed, sound scientific methods to analyze long-term spatiotemporal patterns of TOC have been sought recently. However, it is hard to find enough observed TOC data for watershed management. This study aims to develop a simple, yet reliable framework to analyze the TOC discharge from a complex and large watershed including many sub-basins and non-point sources. This study couples a daily streamflow model (revised TANK model) with two statistical water quality models (nutrition from watersheds and water treatment plants) to predict TOC at important control points in the Nakdong River basin in South Korea for demonstration. This methodology is expected to provide reasonable results even in watersheds with minimal observational data, since the spatial and temporal variation of TOC hydrologic fluxes can be examined by conceptualizing the watershed using discontinuous observation data.
\end{abstract}

Keywords: Hydrologic fluxes; Nakdong River; Total maximum daily loads; Total organic carbon

\footnotetext{
${ }^{*}$ Corresponding author.
} 